\title{
Condições atmosféricas e volumes de aplicação na dessecação de Urochloa ruziziensis e vegetação espontânea ${ }^{1}$
}

\section{Weather conditions and application volumes in the desiccation of Urochloa ruziziensis and spontaneous vegetation}

\begin{abstract}
Dieimisson Paulo Almeida ${ }^{2}$; Paulo César Timossi ${ }^{3}$; Suzete Fernandes Lima ${ }^{4}$; Uadson Ramos da Silva ${ }^{5}$; Edésio Fialho dos Reis ${ }^{3}$
\end{abstract}

Resumo - Na dessecação de cobertura vegetal é comum a ocorrência de falhas, resultante da deposição insuficiente de herbicidas. Dessa forma, torna-se importante conhecer os fatores que possam interferir na aplicação. Com o presente trabalho objetivou-se pesquisar a eficiência da pulverização de volumes de aplicação em diferentes condições atmosféricas. As aplicações foram realizadas ao longo do dia para dessecação de Urochloa ruziziensis e de vegetação espontânea para o estabelecimento de plantio direto. Foi adotado o delineamento de blocos casualizados com quatro repetições em esquema de parcelas subdivididas $2 \times 4$. As parcelas foram constituídas de volumes de aplicação (50 e $\left.200 \mathrm{~L} \mathrm{ha}^{-1}\right)$; e as subparcelas por diferentes condições atmosféricas obtidas com a aplicação em horários distintos (4:30, 10:30, 16:30 e 22:30 horas) ao longo do dia. Na aplicação utilizou-se um pulverizador de pesquisa customizado pressurizado por $\mathrm{CO}_{2} \mathrm{com}$ ponta de pulverização modelo TT 110015, gerando gotas médias. Utilizou-se o herbicida glyphosate na dose de $1,3 \mathrm{~kg}_{\text {ea ha }}{ }^{-1}$. Aos 5, 10, 15 e 20 dias após a aplicação do herbicida foram realizadas avaliações visuais da porcentagem de controle das coberturas vegetais. As condições atmosféricas (temperatura do ar, umidade relativa do ar e velocidade do vento e irradiância) encontradas nos horários de aplicação não exerceram influência na eficácia do herbicida no controle de $U$. ruziziensis em ambos os volumes de aplicação. A redução do volume de calda influência na eficácia de controle da vegetação espontânea em todas as condições atmosféricas em que o herbicida foi aplicado.

Palavras-chaves: glyphosate, horário de aplicação, tecnologia de aplicação de herbicidas

\begin{abstract}
In the desiccation of the vegetation cover, failures are of common occurrence, resulting from insufficient deposition of herbicides. Thus, it becomes important to know the factors that may interfere in the application. The present work aimed to investigate the efficiency of the pulverization of spray volumes in different weather conditions. The applications were carried out during the day for desiccation of Urochloa ruziziensis and spontaneous vegetation for no-tillage establishment. It was adopted a randomized block design with four replications in a split plot

\footnotetext{
${ }^{1}$ Recebido para publicação em 06/09/2014 e aceito em 05/08/2015.

${ }^{2}$ Eng. Agr. Mestre em Agronomia - Doutorando em Agronomia/Produção Vegetal na UNESP - Câmpus Jaboticabal, Jaboticabal, SP. Depto. Fitossanidade, CEP: 14.884-900. E-mail: <dieimissonpa@gmail.com>. (Autor para correspondência).

${ }^{3}$ Professor na Universidade Federal de Goiás - Regional Jataí. Rodovia BR 364, km 192, Setor Parque Industrial, 3800, Caixa postal 03, 75801-615, Jatai, GO, Brasil.

${ }^{4}$ Eng. Agr. Mestre em Agronomia, Doutoranda em Ciências Agrárias/Agronomia no IFGoiano - Campus Rio Verde, Rio Verde, GO, Brasil.

${ }^{5}$ Eng. Agr. Mestre em Agronomia - Secretário de Agricultura de Itarumã - GO. Rua Goiás, n²4, Centro, 75810-000.
} 
scheme of $2 \times 4$. The plots consisted of application volumes (50 and $200 \mathrm{~L} \mathrm{ha}^{-1}$ ); and the subplots consisted of different atmospheric conditions obtained by applying at different times (4:30, 10:30, 16:30 and 22:30 hours) throughout the same day. In the application, it was used a customized sprayer, pressurized by $\mathrm{CO}_{2}$ with the spray nozzle model 110015 TT generating mean drops. It was used glyphosate herbicide at a dose of $1.3 \mathrm{~kg}$ a.e. ha $^{-1}$. At $5,10,15$, and 20 days after herbicide application, it were performed visual assessments of the percentage of control of the vegetation cover. Weather conditions (air temperature, relative humidity, wind speed, and irradiance) found in the application schedules exerted no influence on the efficacy of the herbicide in control of $U$. ruziziensis in both application volumes. Reducing the spray volume had influence on the control effectiveness of the natural vegetation in all weather conditions where the herbicide was applied.

Keywords: glyphosate, application time, herbicide application technology

\section{Introdução}

As regiões produtoras de grãos no Brasil possuem maior parte de suas áreas cultivadas sob Plantio Direto (PD). Em 2012 o país já havia atingido 31,8 milhões de hectares cultivados sob PD (FEBRAPDP, 2014). Este sistema preconiza o cultivo mínimo do solo associado à formação de palhada que proporciona proteção ao solo, supressão de plantas daninhas e ciclagem e disponibilização de nutrientes minerais durante a decomposição da palhada (Alvarenga et al. 2001; Pires, 2011).

Em plantio direto, normalmente utilizase da dessecação da planta de cobertura ou da vegetação espontânea com o herbicida glyphosate, para posterior semeadura da cultura. $\mathrm{O}$ PD quando realizado em diferentes biomas pode apresentar peculiaridades específicas entre os ambientes agricultáveis do Brasil. Assim, as recomendações técnicas para cada situação devem ser baseadas em resultados de pesquisas desenvolvidas nas condições edafoclimáticas locais. Desta forma, torna-se necessário ampliar o conhecimento acerca das técnicas de manejo das coberturas vegetais no momento da dessecação (Velini; Pereira, 2003).

A dessecação é uma operação crítica que requer um bom gerenciamento da qualidade da aplicação do herbicida, pois tanto se pode perder na eficiência de depósito do ativo quanto na eficácia do controle das plantas de cobertura e/ou da vegetação espontânea. Assim, de acordo com a mobilidade do produto a ser aplicado, características morfológicas e anatômicas das folhas e arquitetura dos dosséis das plantas de cobertura ou das espécies que componha a vegetação espontânea além de variações nas condições atmosféricas ao longo do dia, pode-se recomendar o volume de aplicação a fim de reduzir perdas (Scaléa, 1997; Almeida, 2014).

O estudo da tecnologia de aplicação de produtos fitossanitários relacionada com as condições atmosféricas, normalmente é realizado de forma simulada, ou seja, em condições controladas de temperatura, umidade relativa e velocidade de corrente convectiva horizontal (vento) (Moreira Junior; Antuniassi, 2010). Estas metodologias predizem potenciais perdas de depósito de produto no alvo (deriva), porém não se considera as particularidades climáticas regionais e o fenômeno biológico no alvo, as quais se tornam importante à pesquisa local, em condições de campo.

No Brasil, em pulverizações terrestres para o tratamento fitossanitário de culturas graníferas utilizou-se aproximadamente $200 \mathrm{~L}$ $\mathrm{ha}^{-1}$ de calda por décadas. No caso da dessecação de coberturas vegetais para semeadura direta das culturas têm-se reduzido o volume de aplicação, a fim de aumentar o rendimento operacional, e consequentemente, reduzir os custos de produção. A agilidade nesta operação poderá aumentar o período para semeadura de culturas em segunda safra, porém, devem-se atentar às características do herbicida e das plantas para obter qualidade na aplicação do produto (Matuo, 1990).

Considerando a importância do estudo sobre os fatores que possam influenciar nas 
aplicações de produtos fitossanitários, objetivouse verificar a eficiência da pulverização de dois volumes de aplicação em quatro condições atmosféricas distintas ao longo do dia na dessecação de Urochloa ruziziensis e vegetação espontânea para o estabelecimento de plantio direto.

\section{Material e Métodos}

A presente pesquisa foi conduzida no ano de 2013 nas seguintes coordenadas: $-17^{\circ} 55^{\prime}$ $31,78^{\prime \prime}$ S e $51^{\circ} 42^{\prime} 36,17^{\prime \prime} \mathrm{O}$. A região conta com uma altitude média de 680 metros e precipitação pluviométrica anual entre 1.650 a 1.800 milímetros, distribuída entre os meses de setembro a abril, com temperatura média em torno de $25{ }^{\circ} \mathrm{C}$ (Mariano; Scopel, 2001). Os dados meteorológicos durante o período de condução do experimento estão apresentados na Figura 1 (22/10 a 20/11/14).

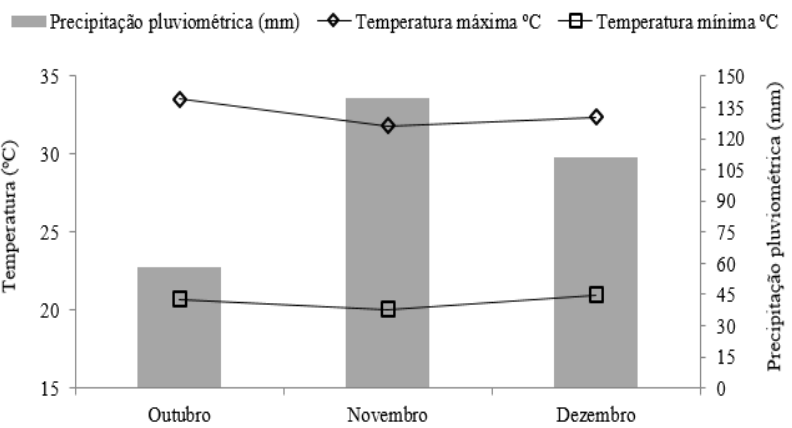

Fonte: Estação meteorológica do INMET situada no Campus Jatobá da UFG - Regional Jataí, GO a 900 metros da área experimental.

Figura 1. Temperatura do ar máxima e mínima média e precipitação total entre os dias 20 de outubro de 2014 a 10 de dezembro de 2014.

O experimento foi conduzido em blocos casualizados, com quatro repetições, onde os tratamentos foram dispostos em esquema de parcelas subdivididas $2 \times 4$. As parcelas foram constituídas de dois volumes de aplicação (50 e $200 \mathrm{~L} \mathrm{ha}^{-1}$ ) e as subparcelas por diferentes condições atmosféricas obtidas com a aplicação em horários distintos (4:30, 10:30, 16:30 e 22:30 horas) ao longo do dia. Cada parcela foi constituída por área de $200 \mathrm{~m}^{2}(40 \times 5 \mathrm{~m})$ e as subparcelas por área de $50 \mathrm{~m}^{2}(10 \times 5 \mathrm{~m})$.

Os tratamentos obtidos por meio da associação dos volumes e horários de aplicação do herbicida glyphosate foram aplicados em dois ensaios, nos quais foram adotadas as coberturas vegetais Urochloa ruziziensis e vegetação espontânea (composta principalmente por rebrotes de sorgo granífero cultivar DKB 550 e Digitaria horizontalis), onde se estabeleceu os mesmos tratamentos (Tabela 1).

Tabela 1. Tratamentos utilizados na aplicação de glyphosate para avaliar a eficiência de dessecação de Urochloa ruziziensis e vegetação espontânea ${ }^{1}$.

\begin{tabular}{lcc}
\hline Tratamentos & $\begin{array}{c}\text { Volume de } \\
\text { aplicação } \\
\left(\mathrm{L} \mathrm{ha}^{-1}\right)\end{array}$ & $\begin{array}{c}\text { Horário de } \\
\text { Aplicação }\end{array}$ \\
\hline 1 & 200 & $4: 30$ \\
2 & 50 & $4: 30$ \\
3 & 200 & $10: 30$ \\
4 & 50 & $10: 30$ \\
5 & 200 & $16: 30$ \\
6 & 50 & $16: 30$ \\
7 & 200 & $22: 30$ \\
8 & 50 & $22: 30$ \\
\hline \multicolumn{1}{l}{ Composta principalmente por rebrotes de sorgo granífero } \\
cultivar DKB 550 e Digitaria horizontalis.
\end{tabular}

Por época da aplicação do herbicida para a dessecação (20 de novembro de 2013), a $U$. ruziziensis possuía acúmulo de massa seca vegetal de $5720 \mathrm{~kg} \mathrm{ha}{ }^{-1}$. Já a vegetação espontânea composta por rebrotes de sorgo granífero (cultivar DKB 550) e Digitaria horizontalis, possuía acúmulo de massa seca vegetal de $2820 \mathrm{~kg} \mathrm{ha}^{-1}$. Para a determinação deste parâmetro foi utilizado um quadro metálico vazado de $0,5 \times 0,5 \mathrm{~m}$, lançado aleatoriamente por três vezes em cada parcela. As plantas contidas nos quadros foram cortadas rente ao solo, acondicionadas em saco de papel e levado para secagem em câmara de circulação forçada de ar à temperatura de $70^{\circ} \mathrm{C}$ por 72 horas 
para posterior pesagem e determinação da massa seca.

O herbicida adotado foi o glyphosate (Roundup Ultra $^{\circledR}$ ) na dose de $1,3 \mathrm{~kg} \mathrm{ha}^{-1}$ do equivalente ácido para a dessecação de ambas as coberturas vegetais. Na calda foi adicionado um adjuvante antiespumante a base de Silano, Goma e veículo QSP (No Spume ${ }^{\circledR}$ ) na concentração de $0,0025 \%$ v/v de calda.

Para a aplicação do herbicida nos dois ensaios, foi utilizado pulverizador de pesquisa costal, pressurizado por $\mathrm{CO}_{2}$ com reservatório de 10 litros constituído de aço inox. A barra de aplicação foi equipada com oito bicos e pontas TT 110015, espaçadas 0,5 $\mathrm{m}$ entre si, trabalhando com uma pressão de $200 \mathrm{kPa}$. Segundo o fabricante (Teejet), com o modelo TT 110015 em pressão de trabalho de $200 \mathrm{kPa}$, obtêm-se uma classe de gotas média. O coeficiente de variação das oito pontas de pulverização fixadas na barra de pulverização foi de $1,9 \%$. A pressão de trabalho nas pontas foi constante de forma que ao pulverizar os dois volumes de aplicação (50 e $200 \mathrm{~L} \mathrm{ha}^{-1}$ ) alteravase apenas a velocidade de deslocamento do conjunto pulverizador e a concentração da calda com o herbicida.

As condições atmosféricas (temperatura, umidade relativa e velocidade do vento) referentes à dessecação das coberturas vegetais (Tabela 2) foram monitoradas por meio de termohigroanemômetro digital da marca Instrutherm, adotando-se oito coletas das condições atmosféricas para cada período da pulverização, para obtenção de médias dos valores.

Tabela 2. Condições atmosféricas em cada horário de aplicação do herbicida glyphosate nas coberturas vegetais em estudo.

\begin{tabular}{cccccc}
\hline Horário & $\begin{array}{c}\text { Condição atmosférica } \\
(\mathrm{CA})\end{array}$ & $\begin{array}{c}\text { Temperatura } \\
\left({ }^{\circ} \mathrm{C}\right)\end{array}$ & $\begin{array}{c}\text { UR do ar } \\
(\%)\end{array}$ & $\begin{array}{c}\text { Velocidade do } \\
\text { vento }\left(\mathrm{km} \mathrm{h}^{-1}\right)\end{array}$ & $\begin{array}{c}\text { Irradiância } \\
\left(\mathrm{kJ} / \mathrm{m}^{2}\right)\end{array}$ \\
\hline $4: 30$ & 1 & 20,3 & 87,4 & 0,8 & 0 \\
$10: 30$ & 2 & 33,5 & 60,0 & 2,9 & 2.277 \\
$16: 30$ & 3 & 36,3 & 36,5 & 5,7 & 1.090 \\
$22: 30$ & 4 & 24,1 & 72,3 & 8,7 & 0 \\
\hline
\end{tabular}

Já os dados de Irradiância (Tabela 2) foram obtidos da estação meteorológica automática do INMET situada no Câmpus Jatobá da UFG - Regional Jataí, GO a 875 metros da área experimental. $\mathrm{O}$ tempo médio de operação para realizar a aplicação nos dois ensaios, em cada horário (10:30, 16:30, 22:30 e 4:30 horas) foi de 40 minutos.

Aos 5, 10, 15 e 20 dias após a aplicação (DAA) do herbicida foram realizadas avaliações visuais da porcentagem de controle das coberturas vegetais por meio de escala percentual de notas, na qual $0 \%$ correspondeu a nenhuma injúria visível nas plantas e $100 \%$, à morte das plantas (SBCPD, 2000).

Para os dados obtidos de porcentagem de controle das coberturas vegetais, realizou-se a análise de variância e as médias comparadas pelo teste Tukey ao nível de $5 \%$ de significância.

\section{Resultados e Discussão}

Aos 5 DAA as porcentagens de controle da $U$. ruziziensis não foram influenciadas pelos dois volumes de aplicação, enquanto que as condições atmosféricas (CA) interferiram na porcentagem de controle. Na CA 4, obteve-se a maior média de eficácia de controle, porém não se diferiu estatisticamente das condições atmosféricas 1 e 2 (Tabela 3). Aos 10, 15 e 20 dias após aplicação verifica-se que os fatores estudados não interferiram na dessecação da $U$. ruziziensis. Ainda, verifica-se que a partir da avaliação realizada aos 10 DAA obteve-se eficácia de controle acima de $80 \%$ nos dois volumes aplicados nas condições 1, 3 e 4 . 
Somente na condição atmosférica 1 constatouse controle abaixo do considerado satisfatório (79,4\% de controle) (SBCPD, 2000). Portanto, mesmo sob condições desfavoráveis de temperatura e umidade relativa (Tabela 2), constata-se eficácia no controle de $U$.ruziziensis nos volumes de 200 e $50 \mathrm{~L} \mathrm{ha}^{-1}$ (Tabela 3).

Tabela 3. Valores de F, DMS, coeficientes de variação (CV\%), aplicado às médias de eficácia de controle, aos 5, 10, 15 e 20 dias após a aplicação (DAA) do herbicida glyphosate ${ }^{2}$ em Urochloa $^{2}$ ruziziensis.

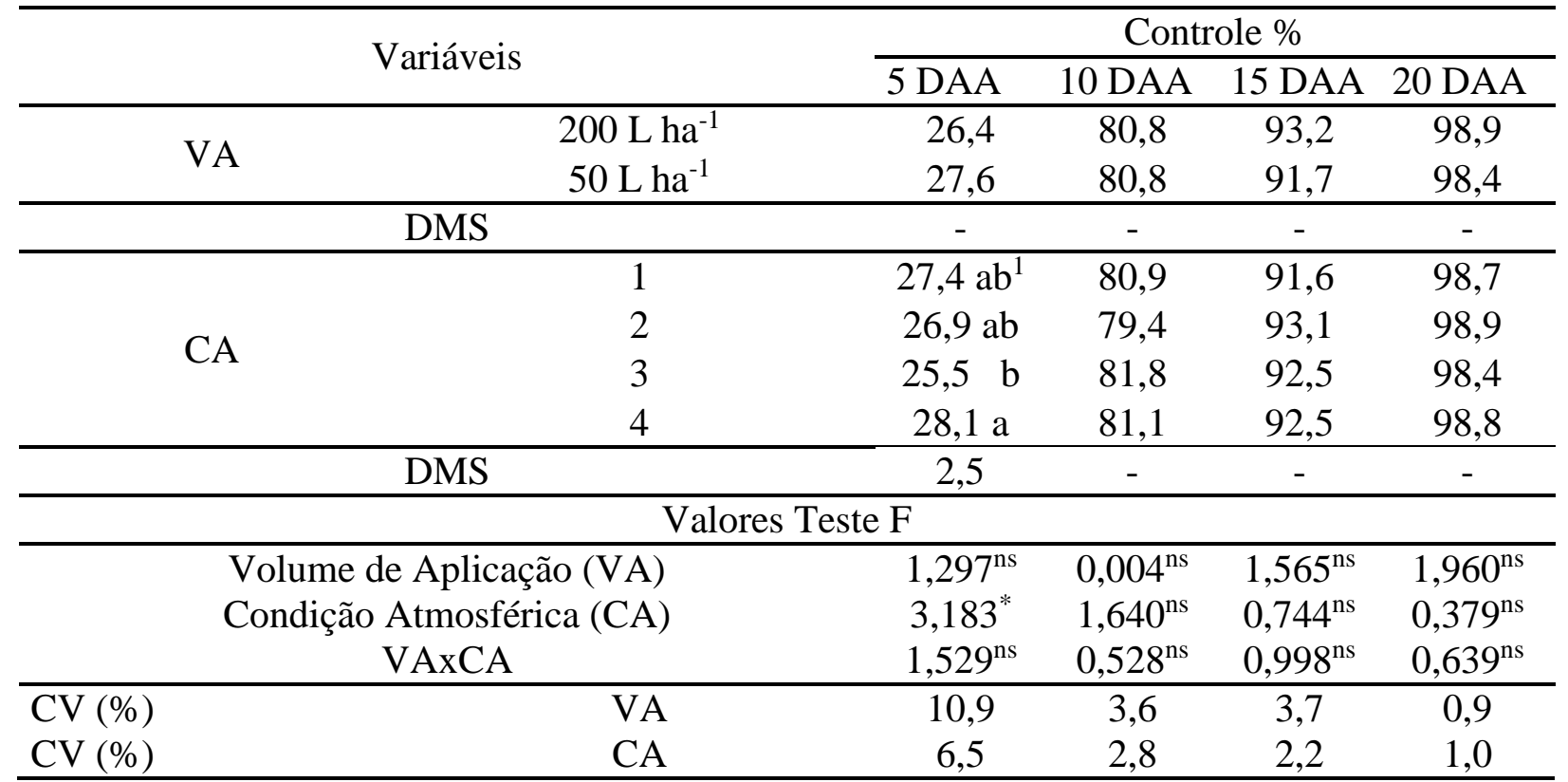

${ }^{n}{ }^{n}$ Não significativo a 5\% de significância, ${ }^{*}$ Significativo a 5\% de significância. ${ }^{1}$ Médias seguidas por letras diferentes, na mesma coluna, não diferem entre si, pelo teste de Tukey $(p<0,05) .{ }^{2}$ Glyphosate (Roundup Ultra ${ }^{\circledR}$ ) na dose de 1,3 $\mathrm{kg} \mathrm{ha}^{-1}$ de e.a. + antiespumante $\left(\right.$ No Spume ${ }^{\circledR}$ ) na concentração de $0,0025 \%$ de v/v.

Aos 10 DAA verificou-se que os volumes de calda e as condições meteorológicas em que o herbicida foi aplicado proporcionaram controle da $U$. ruziziensis para o plantio direto. Ressalta-se que a aplicação de glyphosate em $U$. ruziziensis 10 dias antes da semeadura de culturas graníferas como a soja e o girassol não causa prejuízos a produtividade (Nepomuceno et al., 2012; Giancotti, 2012). Nunes et al. (2009), verificaram resultados similares para o manejo químico de Urochloa decumbens, no qual recomenda-se a dessecação de 7 a 14 dias antes da semeadura de soja.

Verifica-se que os volumes de aplicação não influenciaram nos valores de eficácia de controle da vegetação espontânea aos 5 DAA. No entanto, nota-se influência das condições atmosféricas 1 e 4, nessas condições obteve-se médias acima de $50 \%$ de controle. A partir dos 10 DAA verifica-se que os volumes de aplicação e as condições atmosféricas não interferiram na dessecação da vegetação espontânea (Tabela 4).

Aos 15 e 20 DAA o volume de $200 \mathrm{~L} \mathrm{ha}^{-}$ 1 apresentou incremento de 2,7 e $1,9 \%$ no controle da vegetação espontânea, ao comparar com o valor de porcentagem de controle proporcionada pelo volume de $50 \mathrm{~L} \mathrm{ha}^{-1}$. A menor eficiência constatada na aplicação com $50 \mathrm{~L} \mathrm{ha}^{-1}$ ocorreu devido ao efeito 'Guarda Chuva' proporcionado pela sobreposição de folhas de sorgo sobre as plantas de Digitaria horizontalis. Portanto, ao aplicar o herbicida em pós-emergência em áreas de pousio pode-se ter dificuldade em conseguir uma boa deposição e/ou cobertura no terço médio e inferior), pois 
as plantas não possuem os mesmos estratos vegetais (Almeida, 2014; Scaléa, 1997).

Verificou-se que a partir dos 10 DAA obteve-se eficácia de controle acima de 92\% com os dois volumes de calda e, nas as condições meteorólogicas em que o herbicida foi aplicado, os valores destes controles foram suficientes para semeadura no plantio direto aos 10 DAA, corroborando com Nepomuceno et al. (2012) e Giancotti (2012) (Tabela 4).

Tabela 4. Valores de F, DMS, coeficientes de variação (CV\%), aplicado às médias de eficácia de controle, aos 5, 10, 15 e 20 dias após a aplicação (DAA) do herbicida glyphosate ${ }^{2}$ em vegetação espontânea.

\begin{tabular}{|c|c|c|c|c|c|}
\hline \multicolumn{2}{|c|}{ Variáveis } & \multicolumn{4}{|c|}{ Controle \% } \\
\hline & & $5 \mathrm{DAA}$ & $10 \mathrm{DAA}$ & $15 \mathrm{DAA}$ & $20 \mathrm{DAA}$ \\
\hline \multirow{2}{*}{ VA } & $200 \mathrm{~L} \mathrm{ha}^{-1}$ & 49,4 & 92,8 & $99,5 \mathrm{a}^{1}$ & 99,9 a \\
\hline & $50 \mathrm{~L} \mathrm{ha}^{-1}$ & 49,4 & 92,8 & $97,6 \mathrm{~b}$ & $97,2 \mathrm{~b}$ \\
\hline \multirow[t]{2}{*}{ DMS } & & - & - & 1,8 & 1,6 \\
\hline & 1 & $49,1 \mathrm{ab}$ & 92,6 & 98,4 & 97,9 \\
\hline \multirow{3}{*}{ CA } & 2 & $50,0 \mathrm{a}$ & 92,9 & 99,3 & 99,3 \\
\hline & 3 & $47,5 \mathrm{~b}$ & 92,5 & 98,6 & 98,8 \\
\hline & 4 & $51,1 \mathrm{a}$ & 93,3 & 98,0 & 98,3 \\
\hline \multicolumn{2}{|l|}{$\overline{D M S}$} & 2,3 & - & - & - \\
\hline \multicolumn{6}{|c|}{ Valores Teste F } \\
\hline \multicolumn{2}{|c|}{ Volume de Aplicação (VA) } & $0,000^{\text {ns }}$ & $0,000^{\text {ns }}$ & $11,441^{*}$ & $28,446^{*}$ \\
\hline \multicolumn{2}{|c|}{ Condição Atmosférica (CA) } & $6,855^{*}$ & $0,256^{\mathrm{ns}}$ & $2,695^{\mathrm{ns}}$ & $1,673^{\mathrm{ns}}$ \\
\hline \multicolumn{2}{|c|}{ VAxCA } & $0,824^{\mathrm{ns}}$ & $1,582^{\mathrm{ns}}$ & $1,068^{\mathrm{ns}}$ & $1,041^{\mathrm{ns}}$ \\
\hline $\mathrm{CV}(\%)$ & $\overline{\mathrm{VA}}$ & 7,5 & 3,2 & 1,6 & 1,5 \\
\hline $\mathrm{CV}(\%)$ & CA & 3,3 & 2,0 & 0,9 & 1,3 \\
\hline
\end{tabular}

${ }^{\text {ns }}$ Não significativo a 5\% de significância, ${ }^{*}$ Significativo a 5\% de significância. ${ }^{1}$ Médias seguidas por letras diferentes, na mesma coluna, não diferem entre si, pelo teste de Tukey $(p<0,05) .{ }^{2}$ Glyphosate (Roundup Ultra ${ }^{\circledR}$ ) na dose de 1,3 $\mathrm{kg} \mathrm{ha}^{-1}$ de e.a. + antiespumante $\left(\right.$ No Spume ${ }^{\circledR}$ ) na concentração de $0,0025 \%$ de v/v.

Ao analisar as condições meteorológicas em que foram realizadas as aplicações do glyphosate nas coberturas vegetais, vale ressaltar que em locais onde a temperatura e a umidade do ar nos períodos matutino e/ou vespertino são ainda mais limitantes de que as encontradas na pesquisa, a alternativa é realizar aplicações noturnas visto que a eficácia do glyphosate não foi prejudicada quando realizada nesse período, ou seja, sem irradiância (Tabela 2). Entretanto, deve-se atentar quanto à molécula herbicida utilizada e a planta alvo a ser controlada, pois as temperaturas mais amenas e ausência da irradiância podem alterar o metabolismo das plantas de forma a influenciar desde a absorção e translocação, quanto à eficácia da molécula herbicida (Ramires et al., 1999; Cieslik et al., 2014).

\section{Conclusões}

As condições atmosféricas (temperatura do ar, umidade relativa do ar e velocidade do vento e irradiância) encontradas nos horários de aplicação não exercem influência na eficácia herbicida do glyphosate em Urochloa ruziziensis com o uso dos volumes de aplicação de 200 e $50 \mathrm{~L} \mathrm{ha}^{-1}$. A redução do volume de calda influencia no controle da vegetação espontânea em todas as condições atmosféricas em que o herbicida foi aplicado, com o volume de $200 \mathrm{~L} \mathrm{ha}^{-1}$ mais eficaz. 


\section{Referências}

ALMEIDA, D.P. Tecnologia de aplicação de herbicidas na dessecação de coberturas vegetais. 2014 52f. Dissertação (Mestrado em Agronomia), Universidade Federal de Goiás, Campus Jataí, Jataí-GO.

ALVARENGA, C.B. et al. Efeito do déficit de pressão de vapor d'água no ar na aplicação de defensivos agrícolas na cultura da laranja. In: SIMPÓSIO INTERNACIONAL DE TECNOLOGIA DE APLICAÇÃO, 6, 2013. Resumos... Londrina, 2013. p.1- 4.

ALVARENGA, R.C. et al. Plantas de coberturas de solo para sistema plantio direto. Informe Agropecuário, Belo Horizonte, v.22, n.208 p.25-36, 2001.

CIESLIK, L.F.; VIDAL, R.A.; TREZZI, M.M. Fomesafen toxicity to bean plants as a function of the time of application and herbicide dose. Acta Scientiarum. Agronomy, v.36, n.3, p.329, 2014.

FEBRAPDP. Federação Brasileira de Plantio Direto na Palha. Evolução da área de plantio direto no Brasil. Disponível em: http://www.febrapdp.org.br. Acessado em: 10 de agosto de 2014.

GIANCOTTI, P.R.F. Período de dessecação de Brachiaria ruziziensis e $B$. brizantha antecedendo o plantio direto do girassol. 2012 39 f. Dissertação (Mestrado em Agronomia). Universidade Estadual Paulista, Faculdade de Ciências Agrárias e Veterinárias, Jaboticabal.

MARIANO, Z.F.; SCOPEL, I. Períodos de deficiências e excedentes hídricos na região de Jataí-GO. In: CONGRESSO BRASILEIRO DE AGROMETEOROLOGIA, 12, 2001, Fortaleza. Resumos... Fortaleza: SBA, 2001. p.333-334.

MATUO, T. Fundamentos da tecnologia de aplicação de agrotóxicos. Jaboticabal, Funep, 1990, 139p.

NEPOMUCENO, M.P. et al. Períodos de dessecação de Urochloa ruziziensis e seu reflexo na produtividade da soja RR. Planta Daninha, v.30, n.3, p.557-565, 2012.

NERY, M.C. et al. Produção de sementes forrageiras. Universidade Federal de Lavras, Departamento de Ciência do Solo. Boletim Técnico, n.88, p.1-47, 2012.

NUNES, A.S. et al. Épocas de manejo químico de Brachiaria decumbens antecedendo o plantio direto de soja. Planta Daninha, v.27, n.2, p.297-302, 2009.

PEREIRA, F.A.R.; VELINI, E.D. Sistemas de cultivo no Cerrado e dinâmica de populações de plantas daninhas. Planta Daninha, v.21, n.3, p.355-363, 2003.

PIRES, W.M. Alteração da fertilidade em solos de Cerrado em função da fitomassa de plantas de cobertura em sistemas de plantio direto. 2011. 29p. Monografia (Curso de Agronomia), Instituto Federal de Educação, Ciência e Tecnologia Goiano - Campus Rio Verde, Rio Verde, GO, 2011.

RAMIRES, A.C. et al. Influência dos diferentes horários de aplicação em pós - emergência dos herbicidas chlorimuron- chlorimuron - ethyl, fomesafen e bentazon no controle de Commelina benghalensis L . Acta Scientiarum. Agronomy, v.21, n.3, p.467-472, 1999.

SCALÉA, M.J. Experiências do manejo de plantas daninhas nas condições do cerrado. In: CONGRESSO BRASILEIRO DA CIÊNCIA DAS PLANTAS DANINHAS, 21, 1997, Caxambu-MG. Palestras e Mesas redondas... Viçosa: Sociedade Brasileira da Ciência das Plantas Daninhas, 1997. p.29-31.

SOCIEDADE BRASILEIRA DA CIÊNCIA DAS PLANTAS DANINHAS. Identificação e manejo de plantas daninhas resistentes aos herbicidas. Londrina: SBCPD, 2000. p.32. 